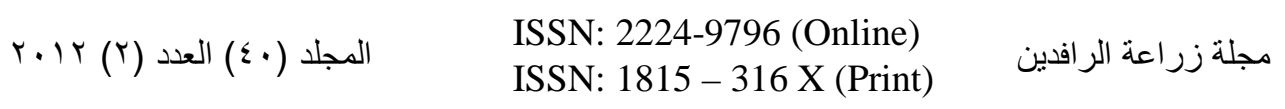

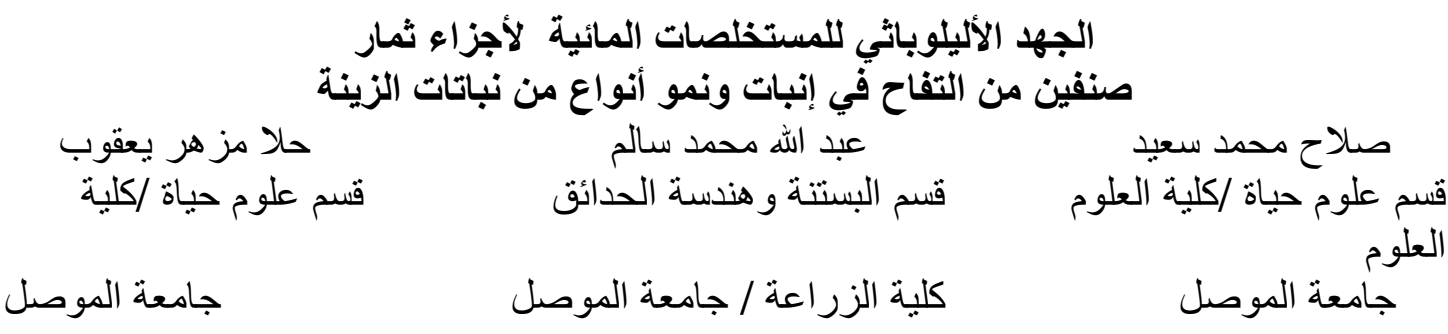

الخلاصة

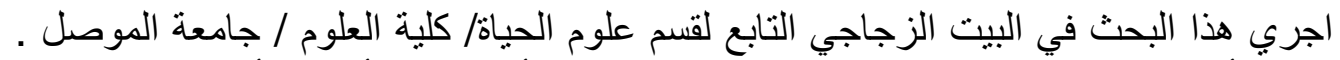

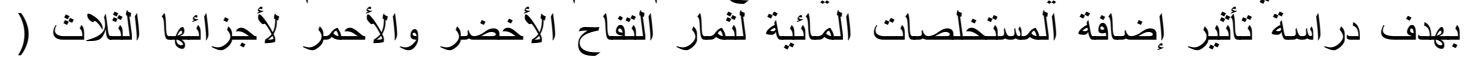

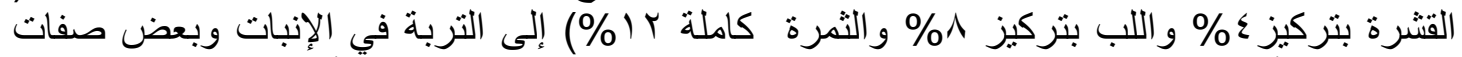
Calendula النمو لثلاث أنواع من نباتات الزينة هي الثبو الكلبهار (الأقحوان) الأبات والبانسية(ورد الصورة) Viofficinalis wittrockiana

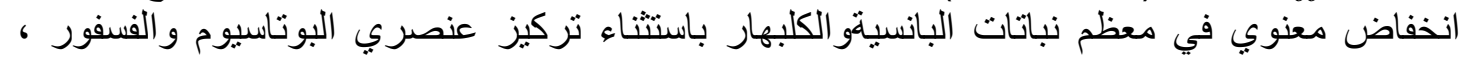

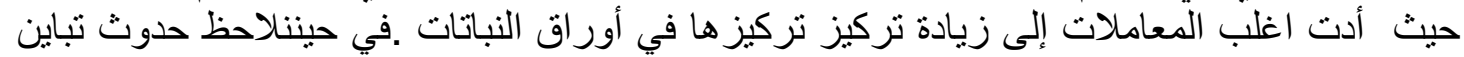

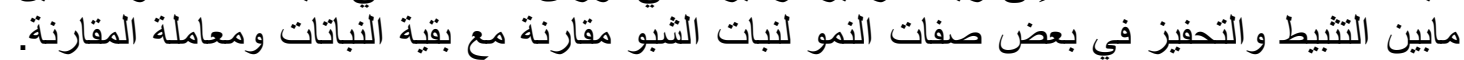

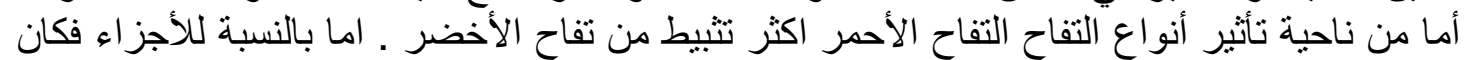

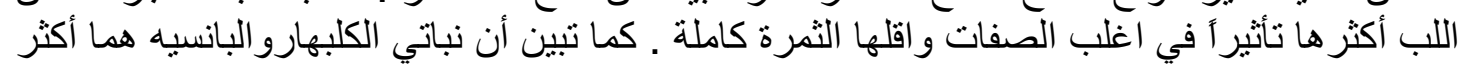

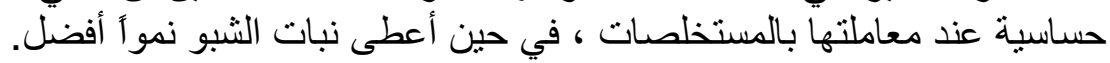

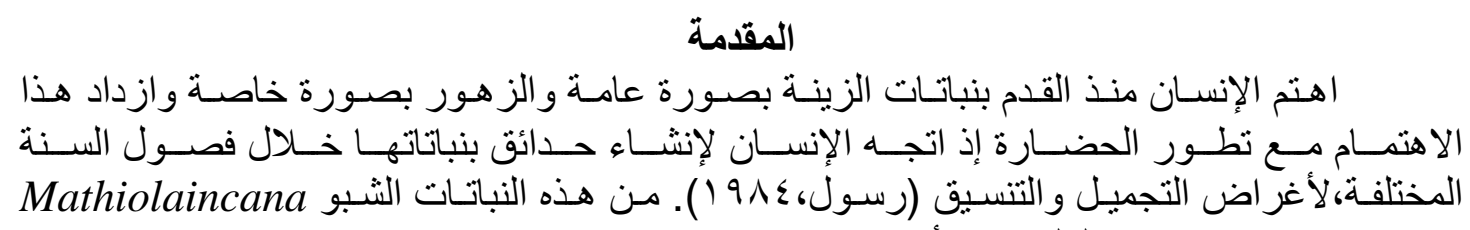

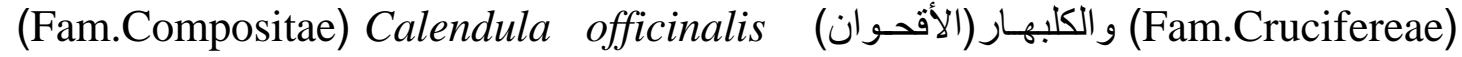

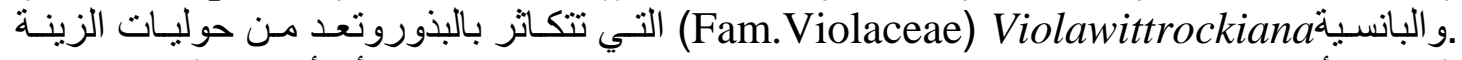

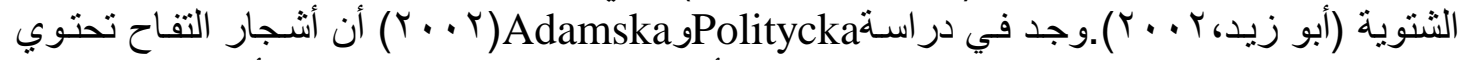

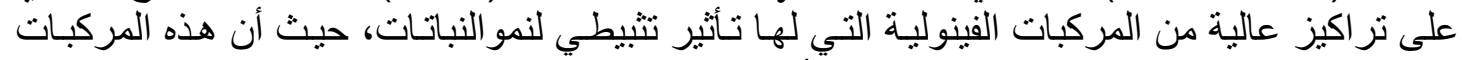

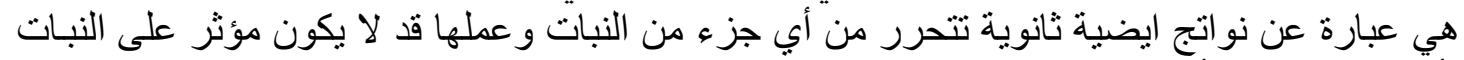

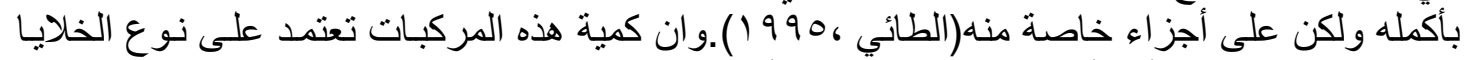

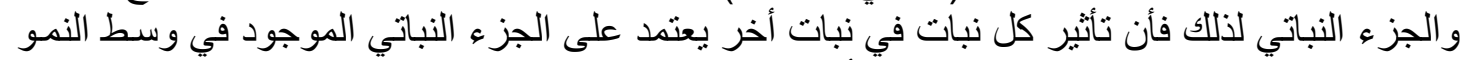

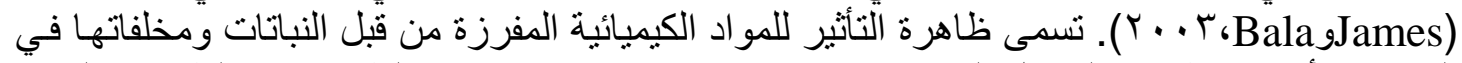

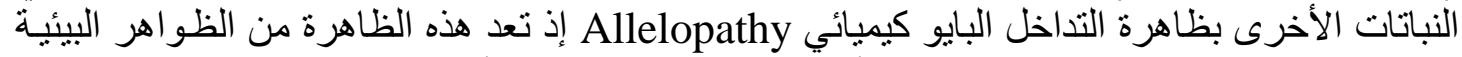

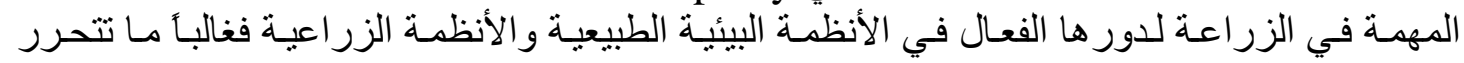

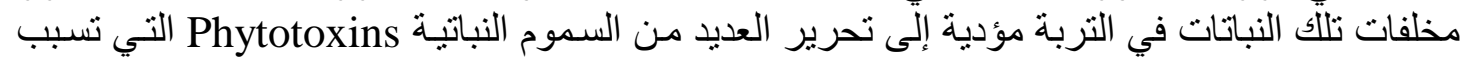

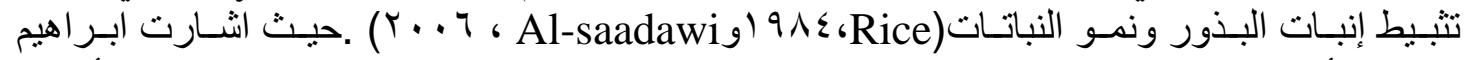

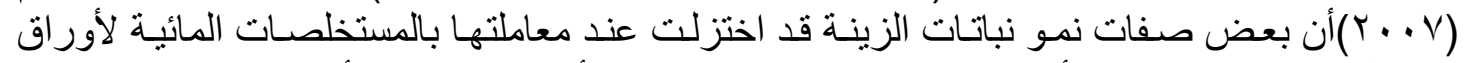

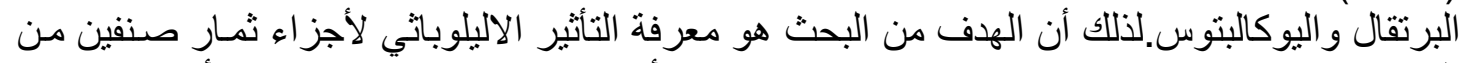

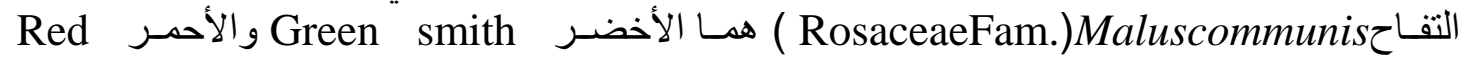
delicious مواد البحث وطرائقه 


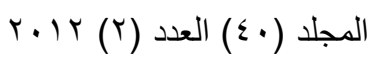

تضمن البحثإجراء تجارب في البيت الزجاجي التابع لقسم علوم الحياة/كلية العلوم /جامعة

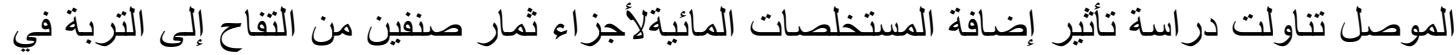

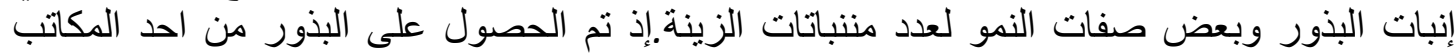

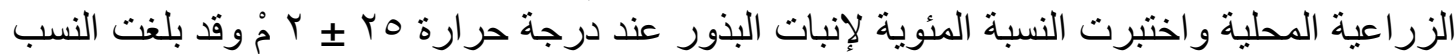

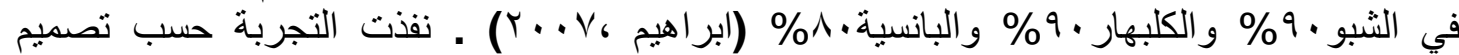

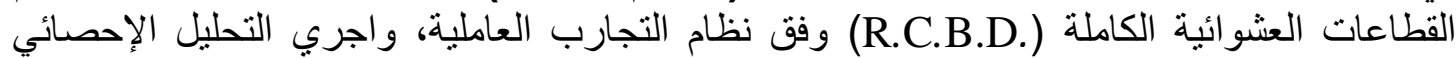

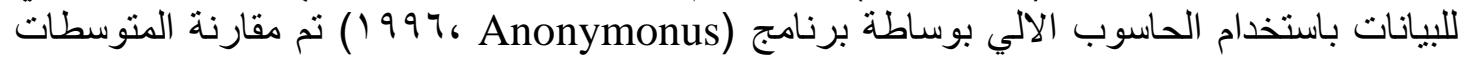

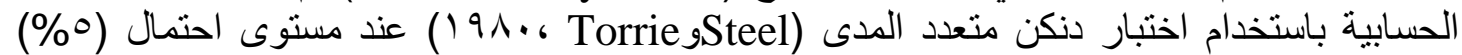

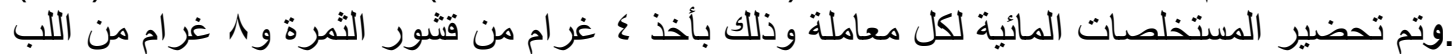

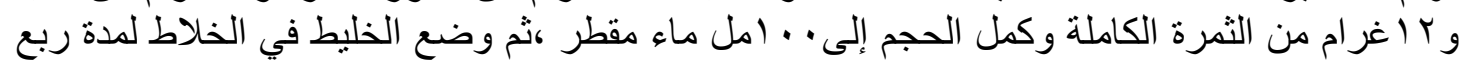

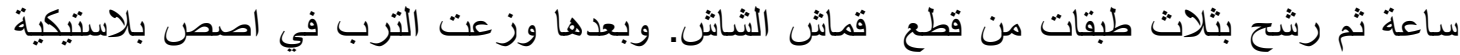

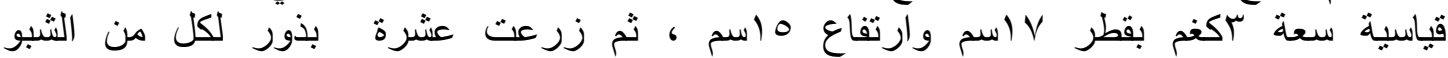

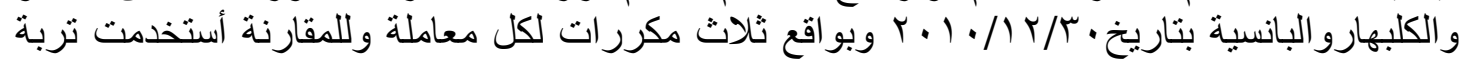

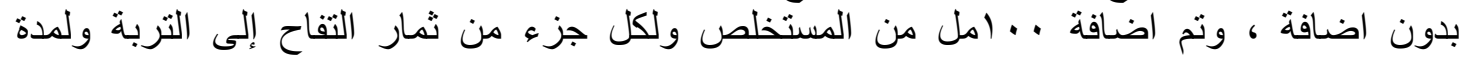

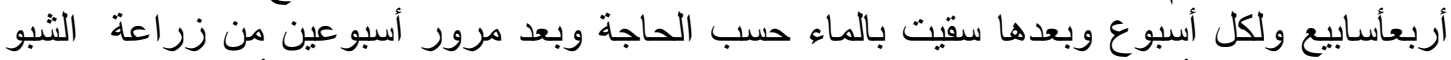

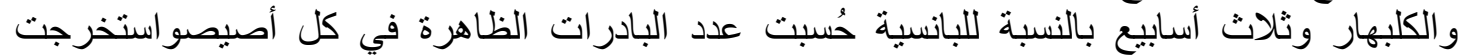

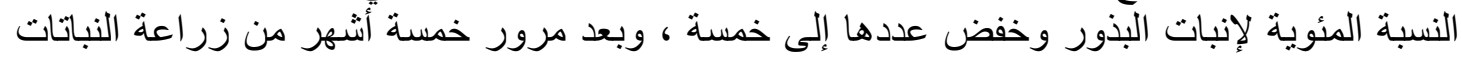

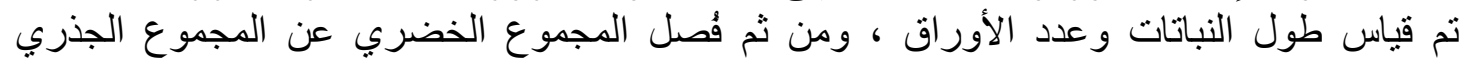

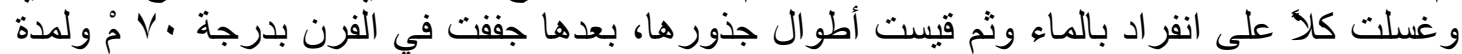

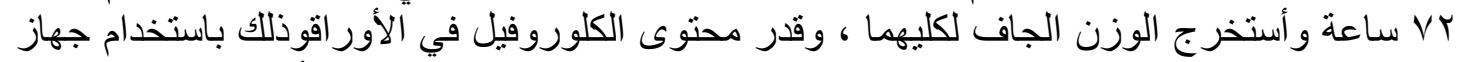

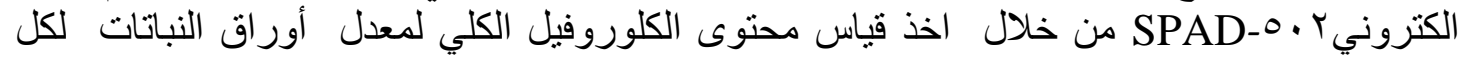
معاملة في كل مكرر، كماتم قياس نسبة النتروجين باستخدام جهاز Microkieldal

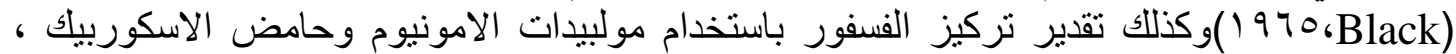

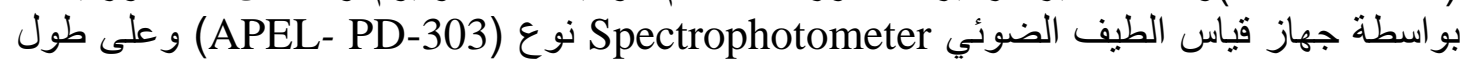

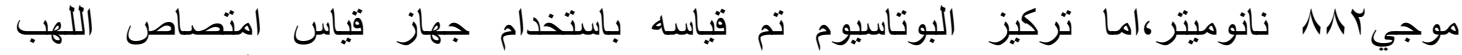
(Flamephotometer)

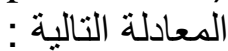

قيمة الصفة لمعاملة المقارنة -قيمة الصفة لمعاملة المستخلص النسبة المئوية للتثبيط

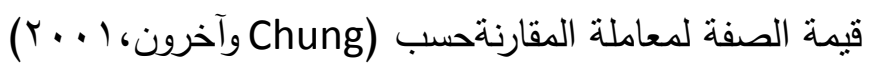

\section{النتائج والمناقشتة}

من الجدول (1) يتبين وجود اختلافات معنويـة بين المتوسطات الحسـابية لصفات نمـ نهو نباتـات

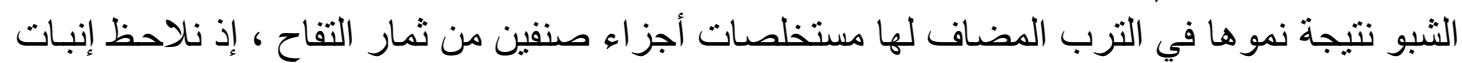

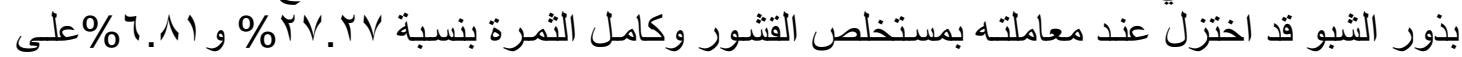

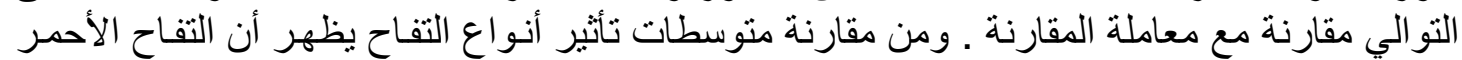

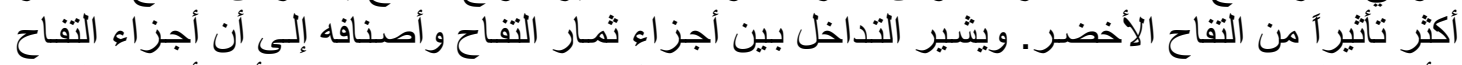

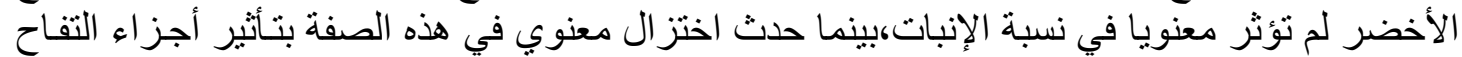

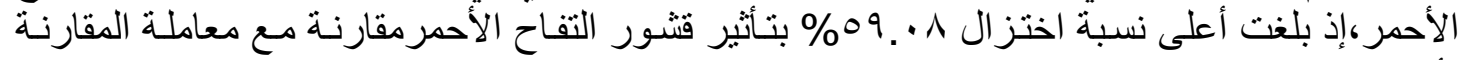

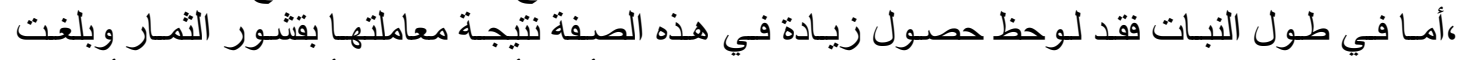

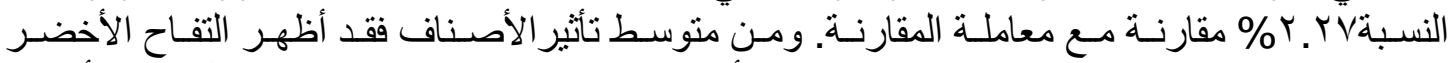

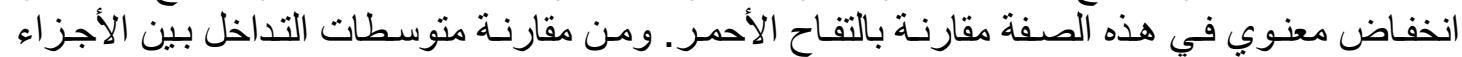

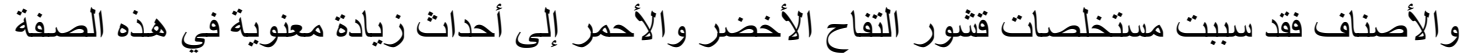

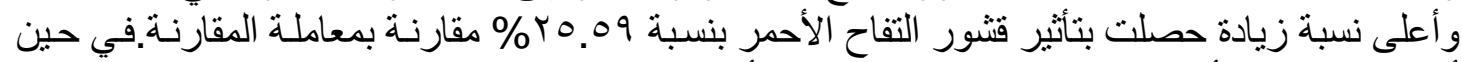

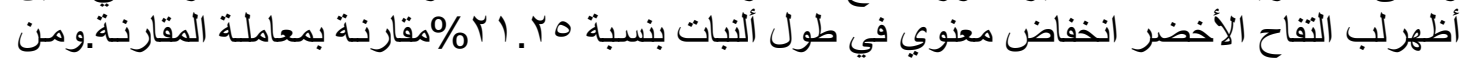




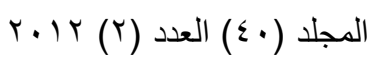
ISSN: 2224-9796 (Online)
ISSN: $1815-316 \mathrm{X}$ (Print)
مجلة زر اعة الرافدين

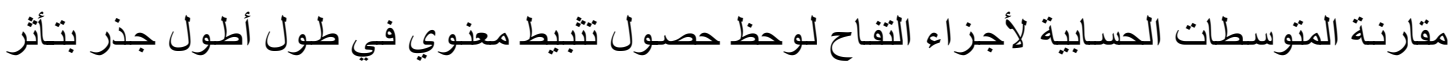

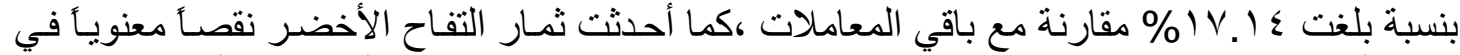

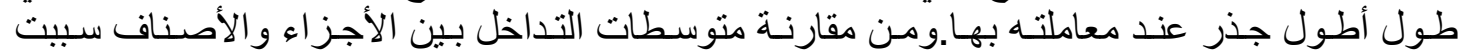

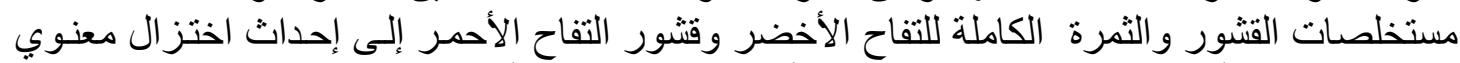

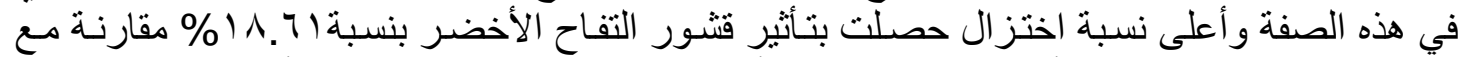

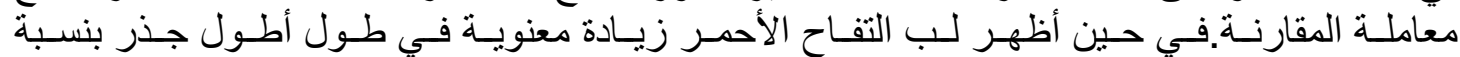

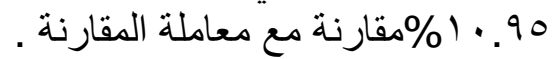

الجدول ( () : تأثنير إضافةالمستخلصات المائية لأجزاء ثمار صنفين من التفاح إلى التربة في إنبات البذور وبعض صفات النمو لنبات الثبو Mathiolaincana.

\begin{tabular}{|c|c|c|c|c|c|c|}
\hline أصناف التفاح تأثثر & مقارنة & ثمرة كاملة & لب ^^\% & قشور ع\%\% & \& & الصفات \\
\hline IVI.Yo & מ & ivo... & $i \wedge . .$. & * V V. & تفاح أخضر & \multirow{3}{*}{$\begin{array}{c}\text { نسبة الإنبات } \\
\text { \% }\end{array}$} \\
\hline \multirow[t]{2}{*}{ ب0r.0. } & أ & •... •0 ب & 17.70 ب & '.... & تفاح أحمر & \\
\hline & سr.r أ & •. זrזب ج & س..رح أ ب & אז.به ج & منوسط تأثنير & \\
\hline 1.. اب & (1).17 & 9.9. & د... & I I I.ru & تفاح أخضر & \multirow{3}{*}{$\begin{array}{c}\text { طول النبات } \\
\text { (سم) }\end{array}$} \\
\hline \multirow[t]{2}{*}{111.19} & ج 1.17 & r & •0.1أ-ج & I IY.V7 & تفاح أحمر & \\
\hline & 17.17 & اس. •ا ب & & $\mid 1, y .01$ & متوسط أجزاء التفاح & \\
\hline r.0r اب & ب. & •r. & •^. آب ج & ד & تفاح أخضر & \multirow{3}{*}{ طذر (سم) أطول } \\
\hline \multirow[t]{2}{*}{111.1.} & 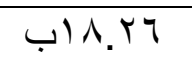 & . 11.0. & $I Y . . Y T$ & 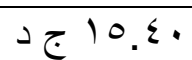 & تفاح أحمر & \\
\hline & דr.^اب & o I I I & س أ.0. & سا & منوسط تأثثير & \\
\hline 1.70 & ع & إ. & r. & سד. • ب & تفاح أخضر & \multirow{3}{*}{ اللمجمو الجاف } \\
\hline \multirow[t]{2}{*}{$1 \cdot .71$} & ع & ع & $i \cdot .80$ & • . . أب & تفاح أحمر & \\
\hline & I. $.7 \varepsilon$ & $1 . .7 \mathrm{~V}$ & 1.71 & 1.77 & منوسط تأنثير & \\
\hline $1 . r q$ & ع & ع & $\{\cdot . \leqslant 7$ & ج & تفاح أخضر & \multirow{3}{*}{ اللوزن الجاف } \\
\hline \multirow[t]{2}{*}{$i \cdot . Y T$} & ع r. • ب ج & q & س & & تفاح أحمر & \\
\hline & ع & & ه. . أ & or. • ب & أجز اء التفاح تأثنر & \\
\hline $119 . \wedge 1$ & اب. & •r. •r أب & •r. •r أب ب & i r. .qr & تفاح أخضر & \multirow{3}{*}{ عدد الأوراق } \\
\hline \multirow[t]{2}{*}{$119 . \mathrm{VT}$} & 11... & .^.^ا أب & IYI.r. & $i r \cdot . V T$ & تفاح أحمر & \\
\hline & 11اب... & 19.00 أ ب & r & $i r . .10$ & أجز اء التفاح تأثير & \\
\hline
\end{tabular}

*البيانات التي تشترك بأحرف متشابه لا يوجد فروق معنوية فيما بينها عند مستوى ٪\% وحسب اختبار دنكن متعدد وفي الوزن الجاف للمجموع الخضري نلاحظ من خلال مقارنة المتوسطات لتأثير كل من أجزاء الثمار

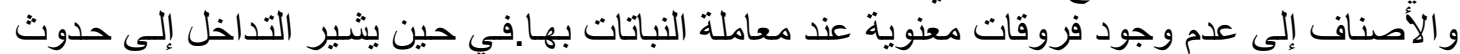

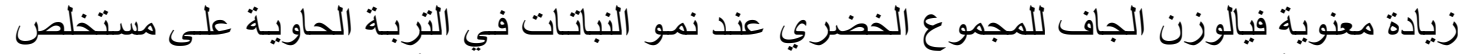

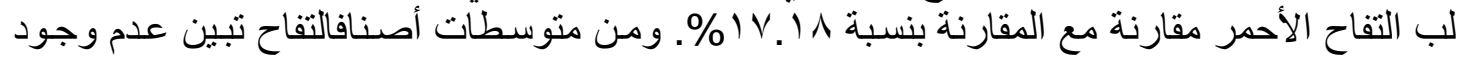

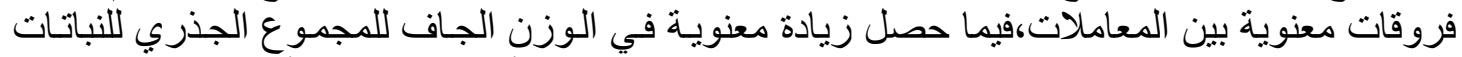

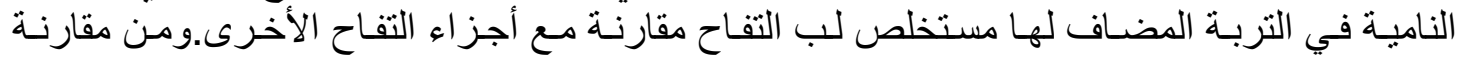




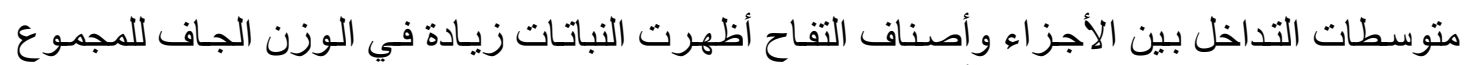

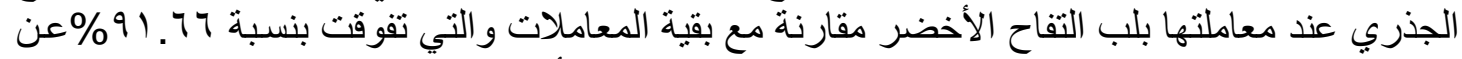

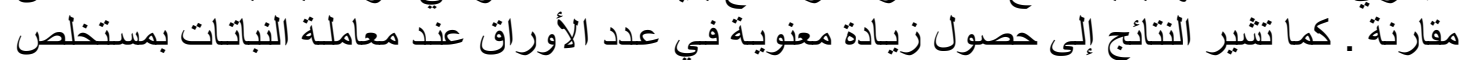

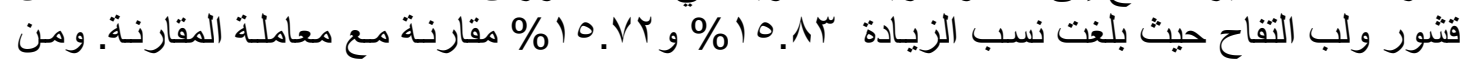

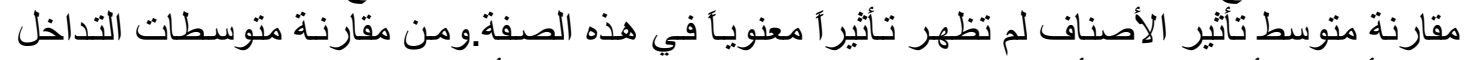

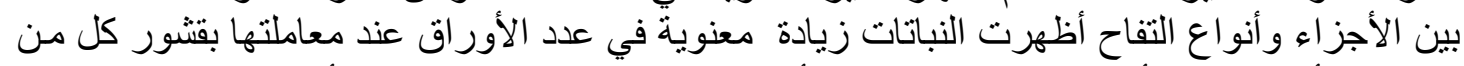

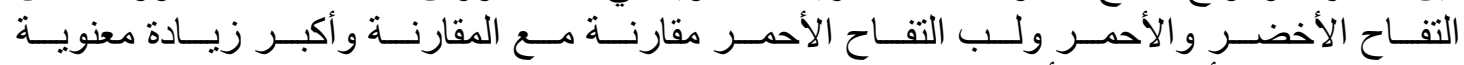

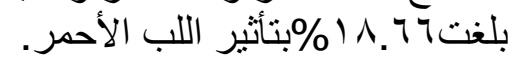

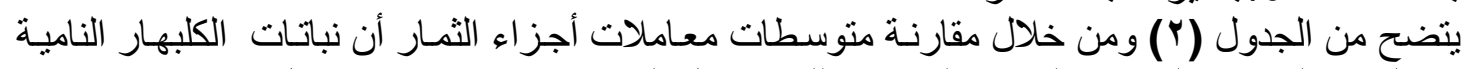

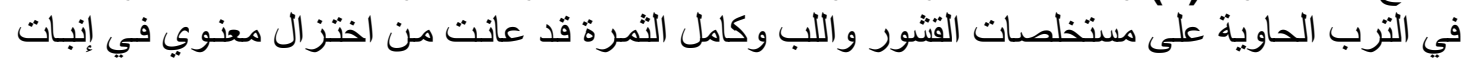

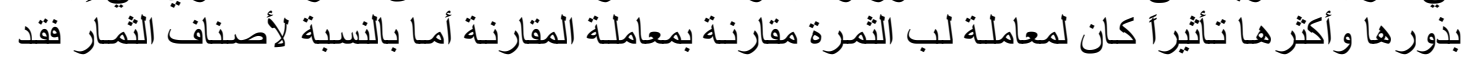

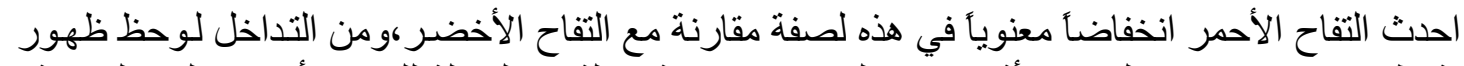

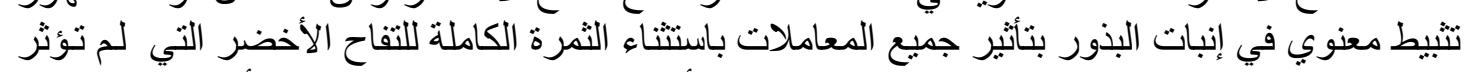

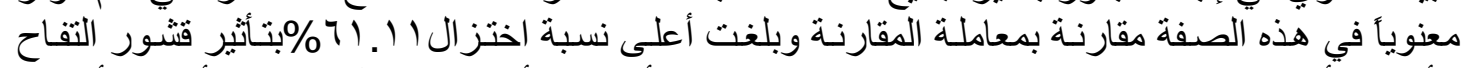

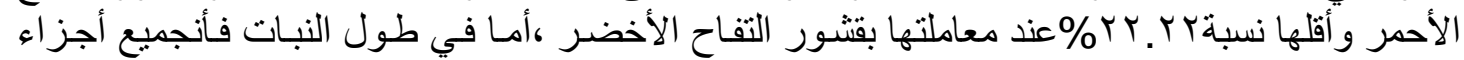

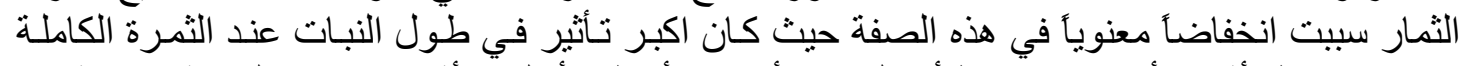

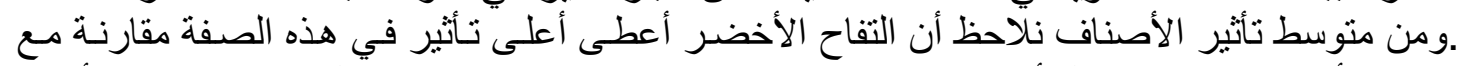

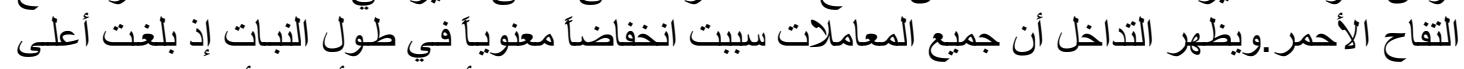

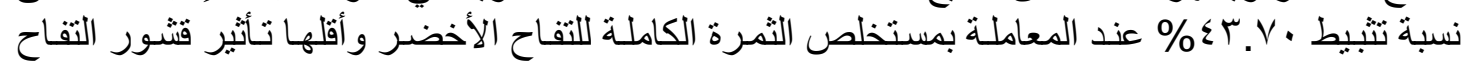

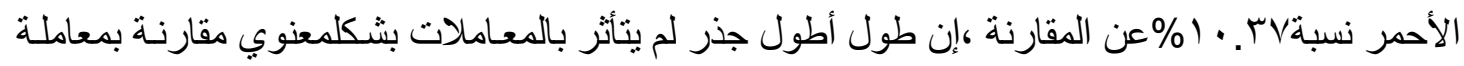

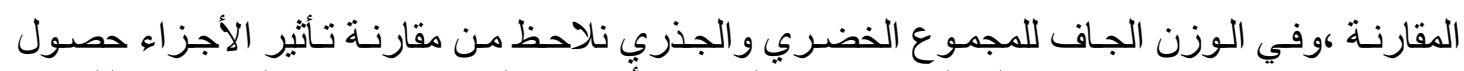

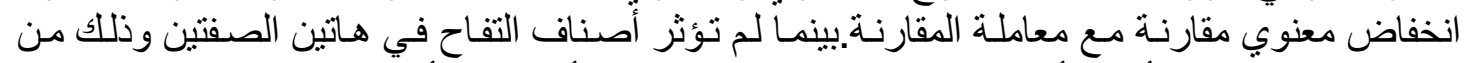

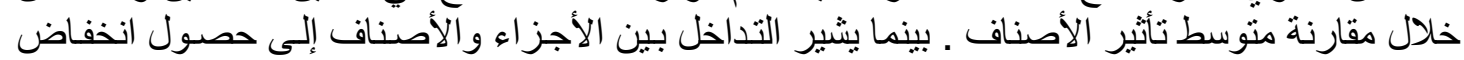

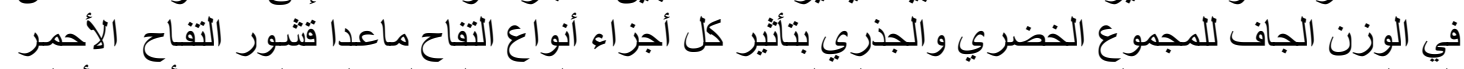

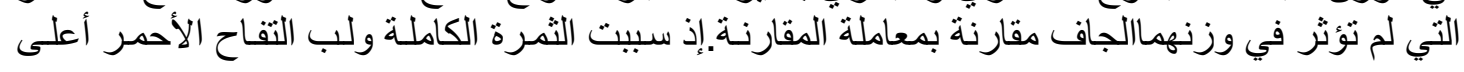

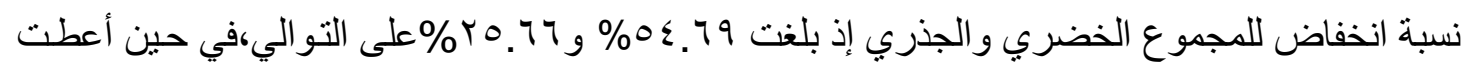

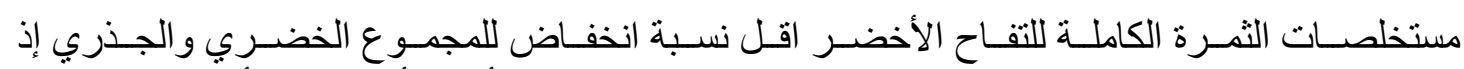

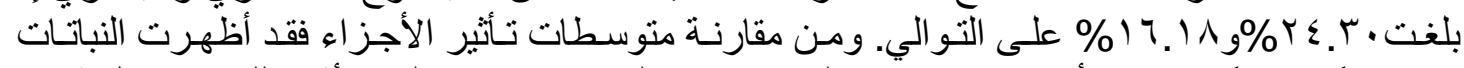

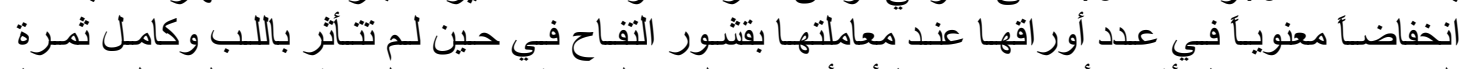

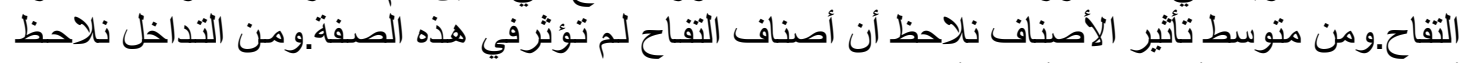

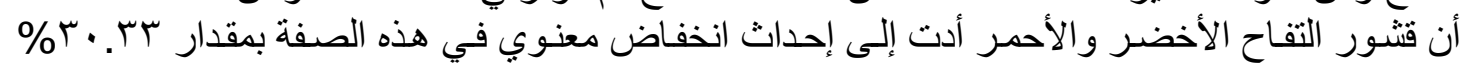

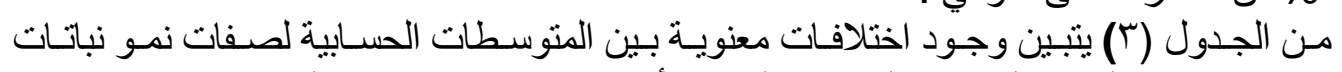

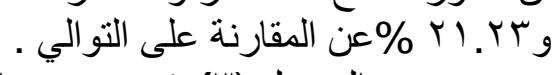

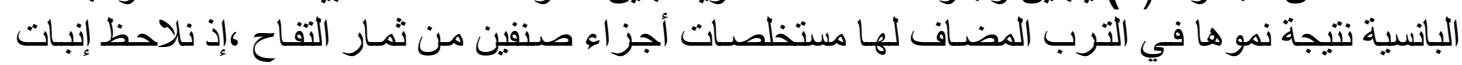

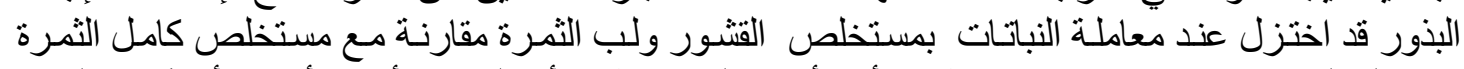

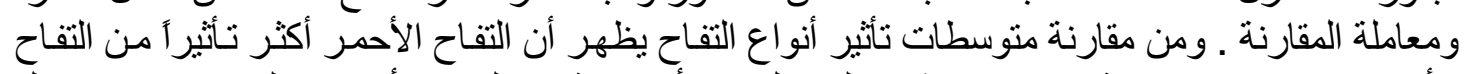

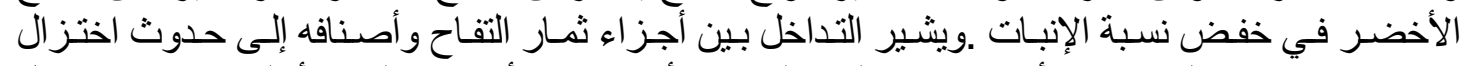

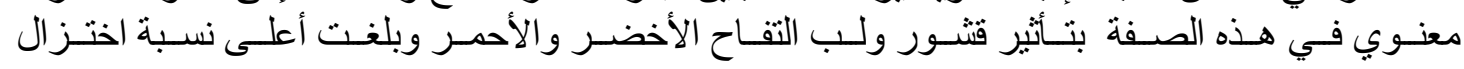

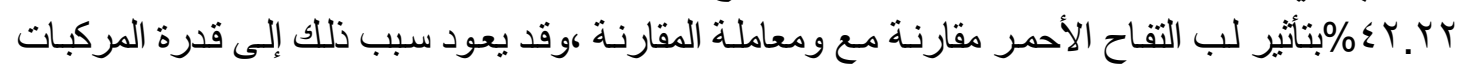

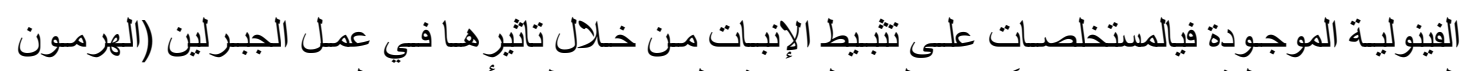

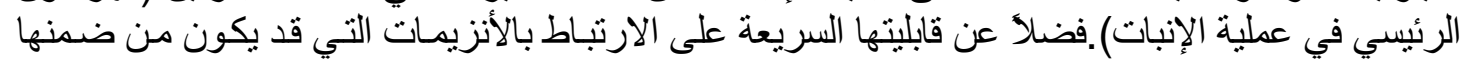

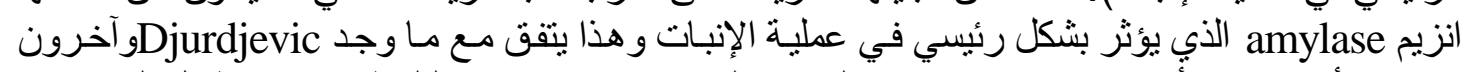

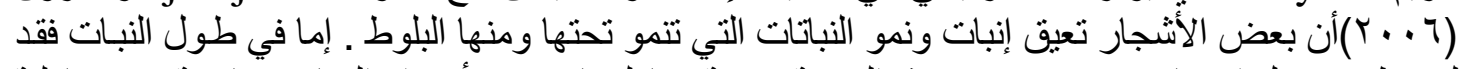

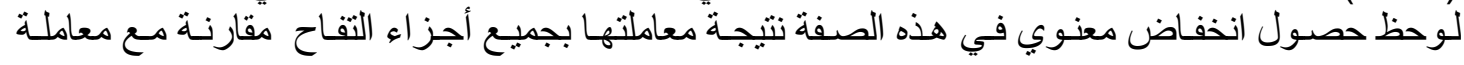


المقارنة من خلال مقارنة متوسطات تأثير أجزاء التفاح ـ ومن متوسط تأثثر الأصناف لم يظهر فرق معنوي

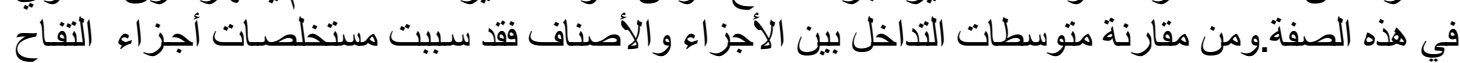

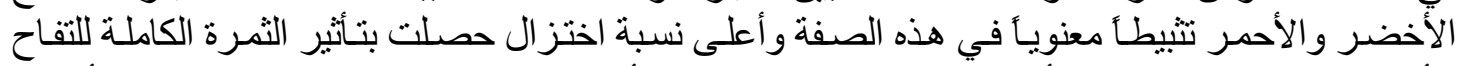

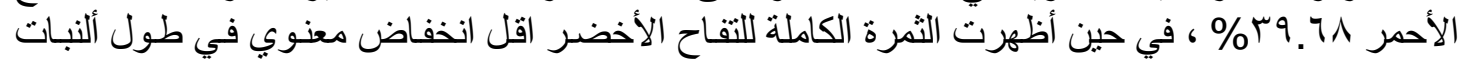

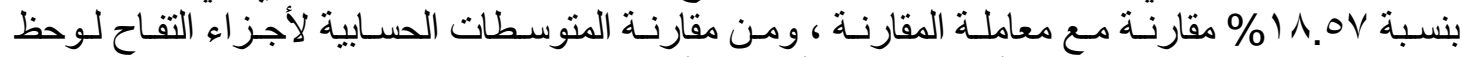

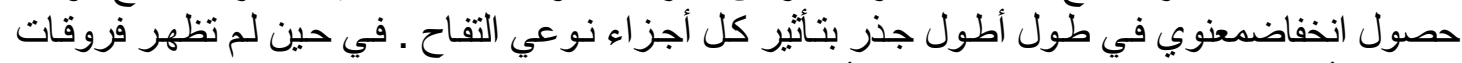
معنوية بتأثثر صنفي التفاح من خلال مقارنة تأثير متوسطاتها.

جدول (r) : تأثنير إضافةالمستخلصات المائية لأجز اء ثمار صنفين من التفاح إلى التربة في إنبات

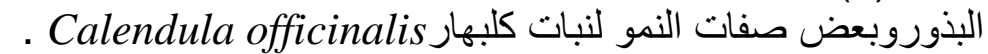

\begin{tabular}{|c|c|c|c|c|c|c|}
\hline متوسط تأثنير & مقارنة & ثمرة كاملة & لب ^^\% & قشور ع\% & & الصفات \\
\hline ivo.Ar & أ $9 . .$. & س & •... & *... & تفاح أخضر & \multirow{3}{*}{$\begin{array}{c}\text { نسبة الإنبات } \\
\text { \% }\end{array}$} \\
\hline \multirow[t]{2}{*}{. } & i9.... & $د \leqslant 0 .$. & oد & oro... & تفاح أحمر & \\
\hline & $9 . .$. & 1. . & •... & ج or.o. & |أجزاء التفاح تأثير & \\
\hline 9.99 & IIT.Y. & ج ج.^r & ج.9. & T. & تفاح أخضر & \multirow{3}{*}{$\begin{array}{c}\text { طول النبات } \\
\text { (سم) }\end{array}$} \\
\hline \multirow[t]{2}{*}{$111 . Y \leq$} & I IT.Y. & & & r. & تفاح أحمر & \\
\hline & I I I.r. & . . & س. & سع. •ا ب & |أجزاء التفاح تأثير & \\
\hline$i r \cdot .7 r$ & . $9.1 ا$ أب & r..r & I YY.VT & 19.97 & تفاح أخضر & \multirow{3}{*}{ طذر (سم) أطول } \\
\hline \multirow[t]{2}{*}{$|r . .1|$} & . 19.1 أ ب & & 19.77 أب & r 19.r ب & تفاح أحمر & \\
\hline & . 19.1 أب & ir..10 & I r I. & 119.70 & أجزاء التفاح تأثير & \\
\hline I 1. & $\mid 1.11$ & VI. & 1.11 ب ج & 1.10 ب ج & تفاح أخضر & \multirow{3}{*}{ اللخجمن الجاف } \\
\hline \multirow[t]{2}{*}{$|1 . Y|$} & $11 . \wedge 1$ & ج・AY & • • & •r. اب & تفاح أحمر & \\
\hline & (1). 1) & 9 9.1 ب & ... ب ب & r & |أجزاء التفاح تأنير & \\
\hline $1 \cdot .9 \leq$ & $11.1 \%$ & ب & & س & تفاح أخضر & \multirow{3}{*}{ اللجذمون الجاف } \\
\hline \multirow[t]{2}{*}{$11 .}$. & 11.11 & & & $11.1 \mathrm{~V}$ & تفاح أحمر & \\
\hline & س 1.1 & •و. • ب ج & ج & ... ب ب & |أجزاء التفاح تأثير & \\
\hline $11 . .0 \mathrm{~V}$ & IIr.l. & ،ر.، أب & 1أ9 1 أب & ج & تفاح أخضر & \multirow{3}{*}{ عدد الأوراق } \\
\hline \multirow[t]{2}{*}{$11 . .9$. } & $1, r .1$. & آي.. ا أب & 11. •أب & & تفاح أحمر & \\
\hline & II I I. & سی. • ا أب & r. & & أجزاء التفاح تأثير & \\
\hline
\end{tabular}

*البيانات التي تشترك بأحرف متشابه لا يوجد فروق معنوية فيما بينها عند مستوى ^\% وحسب اختبار دنكن متعدد

ومن مقارنـة منوسطات التداخل بين الأجزاء والأصناف سبيت مستخلصـات جميع أجزاء التفاح المدى.

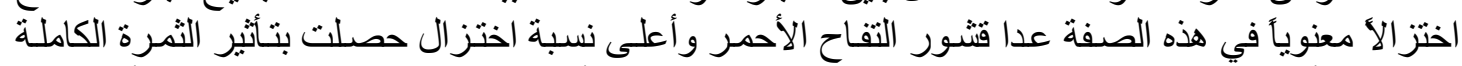

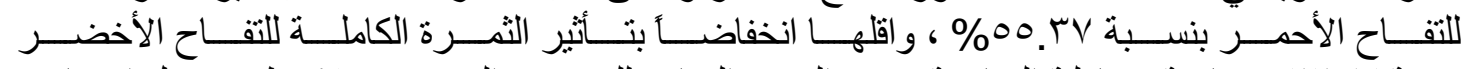

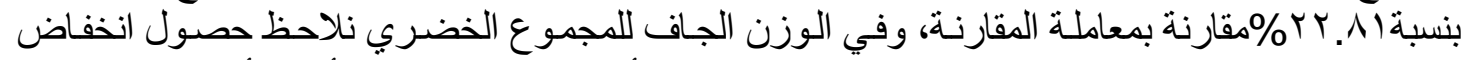

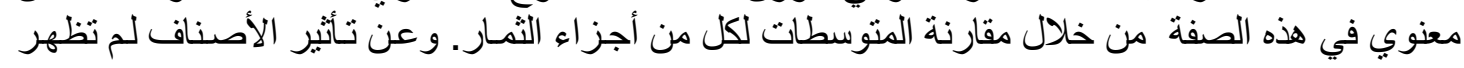




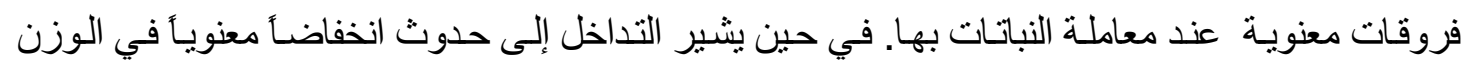

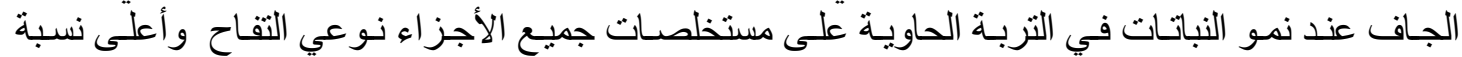

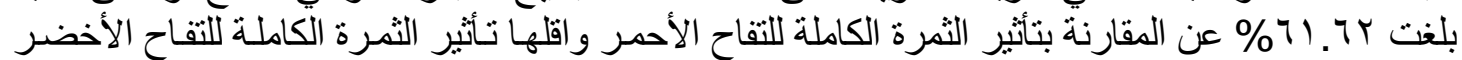

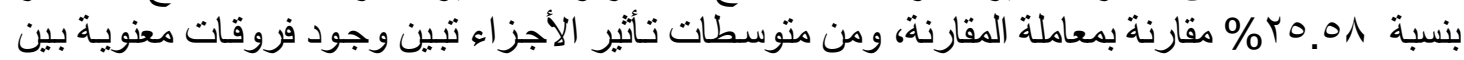

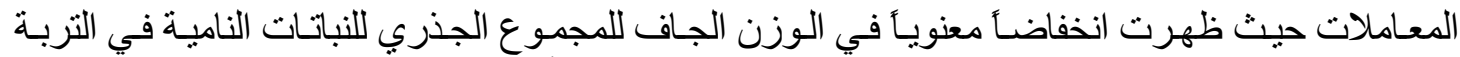

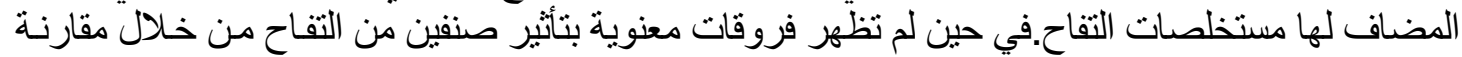

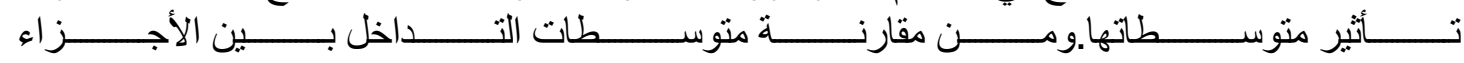

جدول (ب) : تأثنير إضـافة المستخلصـات المائيـة لأجز اء ثــار صنفين مـن التفـاح إلى التربـة في انبـات

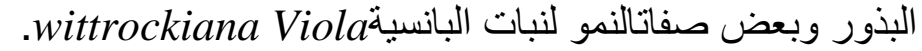

\begin{tabular}{|c|c|c|c|c|c|c|}
\hline أتنأثير سط التفاح & مقارنة & ثمرة كاملة & لب ^^\% & قثور ₹ع\% & 18 & الصفات \\
\hline $170 .$. & IVo... & 1V0... & •... & 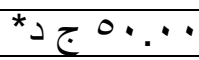 & نضر & \multirow{3}{*}{ نسبة الإنبات } \\
\hline \multirow[t]{2}{*}{ } & $100 .$. & ....10.ب & 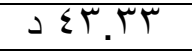 & •...00 ب ج & & \\
\hline & i vo... & I $v \cdot .$. & & . or.o. & جزاء & \\
\hline $10 .$. & $17 . r$. & & • •. & 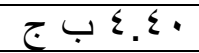 & خضر & \multirow{3}{*}{ 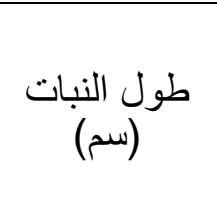 } \\
\hline \multirow[t]{2}{*}{$1 \leq .94$} & $17 . r$. & ج r.^. & •. & "آ ب. ب & & \\
\hline & أ.r. & ب & هـ. & بـ & جز اء & \\
\hline 117.09 & $\mid Y 1.97$ & 17.90 & •. זו ج د. & & خضر & \multirow{3}{*}{ جذر (سم) أطول } \\
\hline \multirow[t]{2}{*}{117.1} & 111.97 & $د 9.1$. & 1Y. & $1 Y \cdot .0$ & حمر & \\
\hline & $1 Y 1.97$ & Vע. & גז.r| & P.TV & & \\
\hline $1 \cdot .7$. & $1 \cdot . \wedge 7$ & & ג & ro. · ب ج & أخضر & \multirow{3}{*}{ 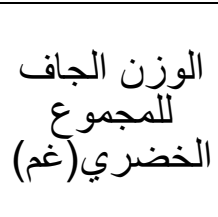 } \\
\hline \multirow[t]{2}{*}{$1 . .00$} & $1 \cdot . \wedge 7$ & د. & كا.0. ب ج & & احمر & \\
\hline & $\{\cdot . \wedge 7$ & & & •0. • ب & & \\
\hline $1 \cdot . \leqslant 7$ & $1 \cdot .9 \leqslant$ & אץ . ج د & דף. & צח. • ب ج & تفاح أخضر & \multirow{3}{*}{ اللوزن الجافوع الجزي (غم) } \\
\hline \multirow{2}{*}{$1 \cdot . \leqslant 0$} & $1 \cdot .9 \varepsilon$ & $د \cdot Y \xi$ & $\Delta \cdot Y Y$ & •. & تفاح احمر & \\
\hline & $1 \cdot .9 \leq$ & דצ'י• & ج & ג & حَ أجزاء & \\
\hline $111 . \leqslant 0$ & 110.7 & & $7^{\wedge .97}$ & •ا. • ا ب ج & تفاح اخضر & \multirow{3}{*}{ عدد الأوراق } \\
\hline \multirow[t]{2}{*}{111.07} & 110.7 & ج.^.^. & r اب ج ج اب & ب11.97 & تفاح احمر & \\
\hline & 110.7 & & • . . & مب.1ا ب & تأثثِير أجز اء & \\
\hline
\end{tabular}

״البيانات التي تشترك بأحرف متثابه لا يوجد فروق معنوية فيما بينها عند مستوى احتمال ٪\% وحسب اختبار دنكنمتعدد

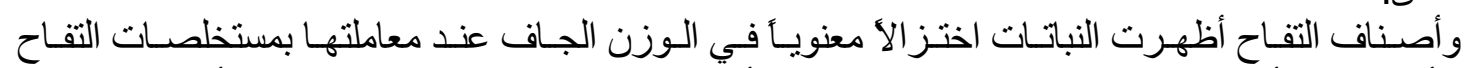

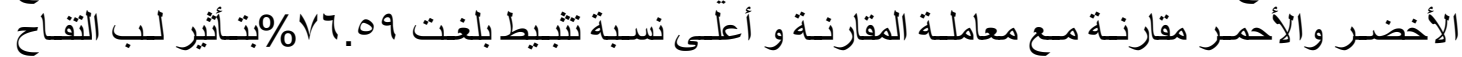

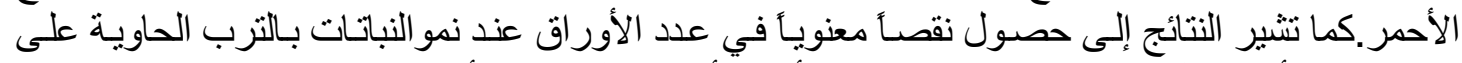

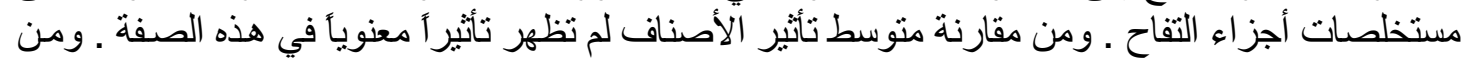




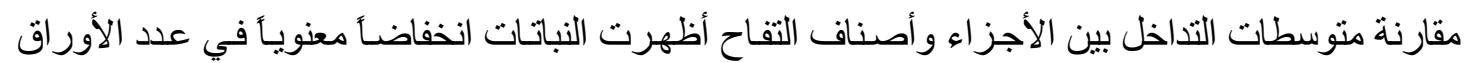

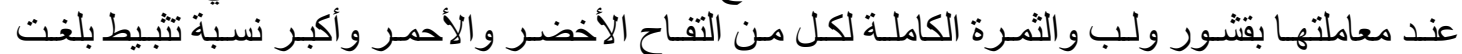

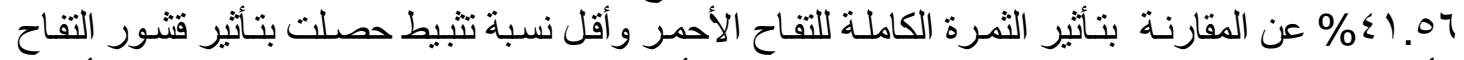

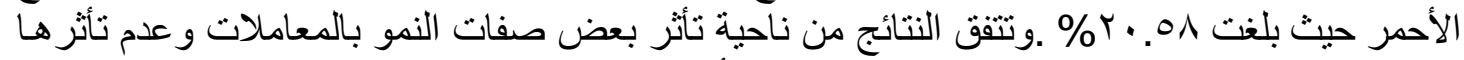

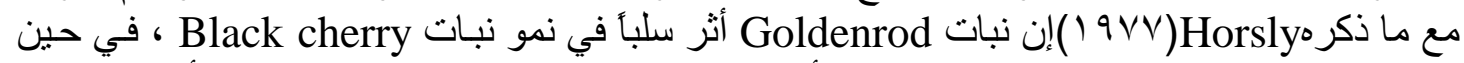

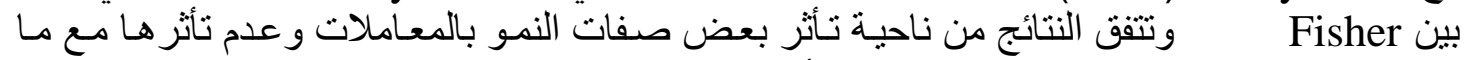

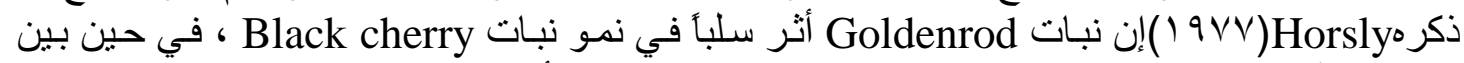

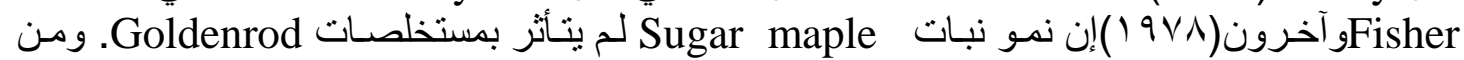

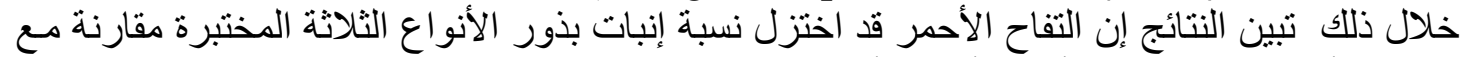

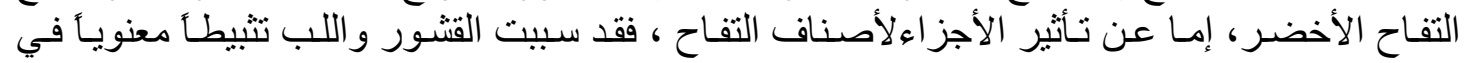

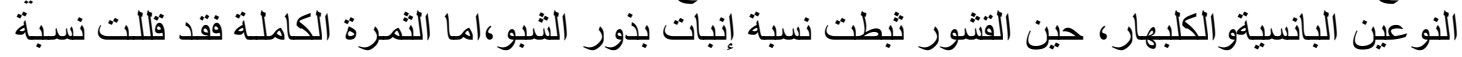

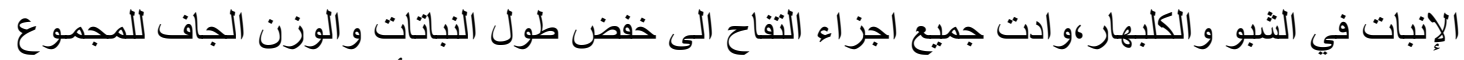

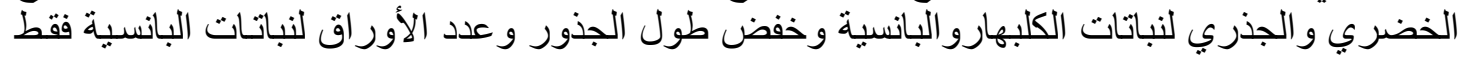

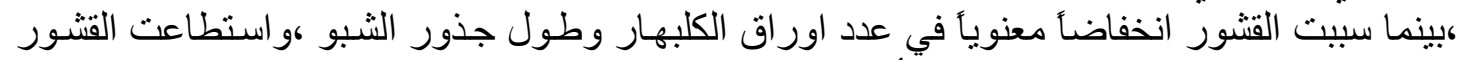

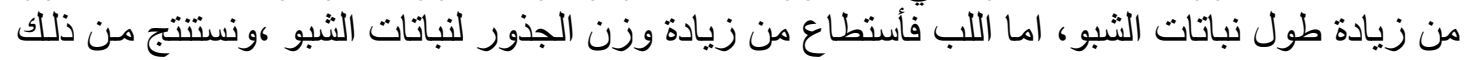

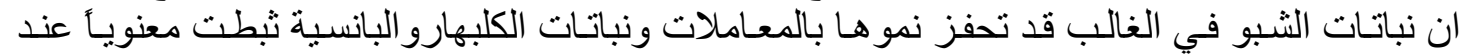

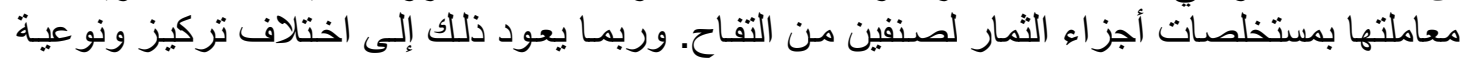

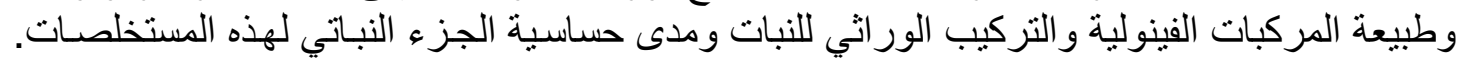

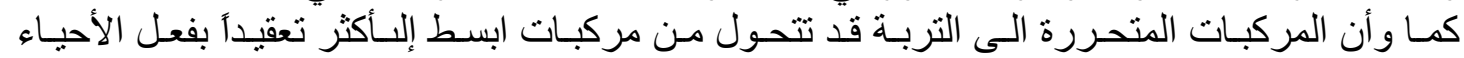

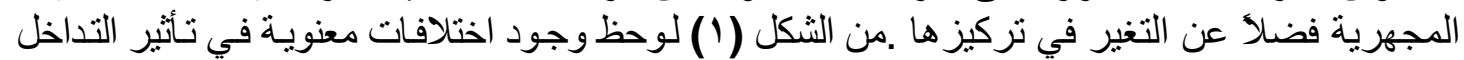

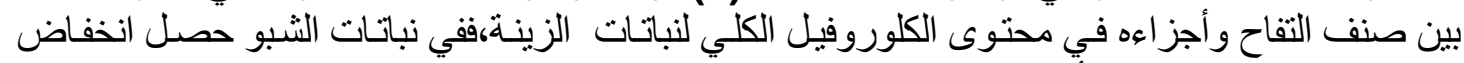

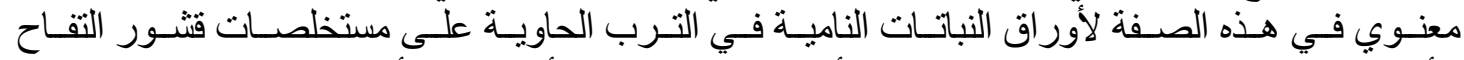

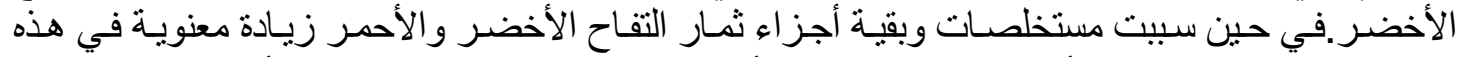

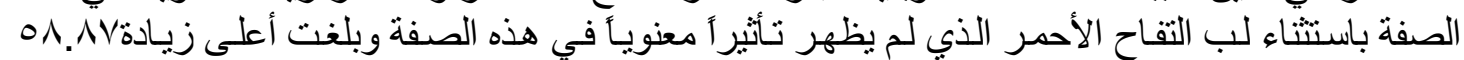

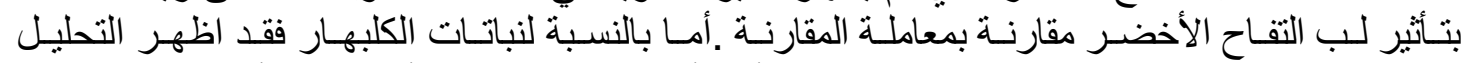

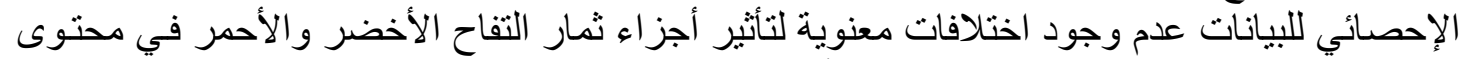

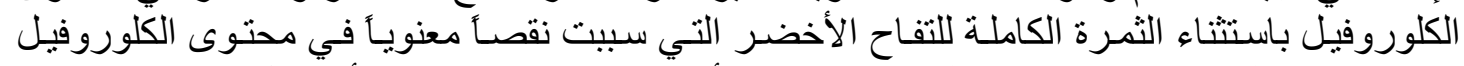

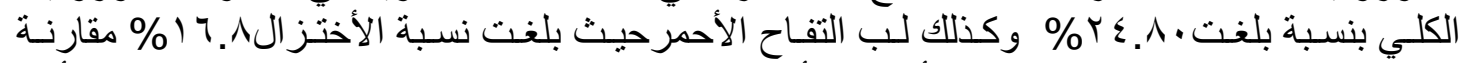

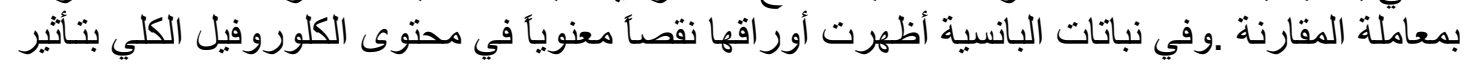

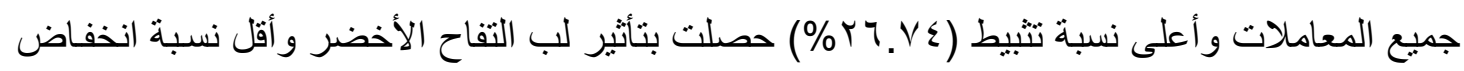

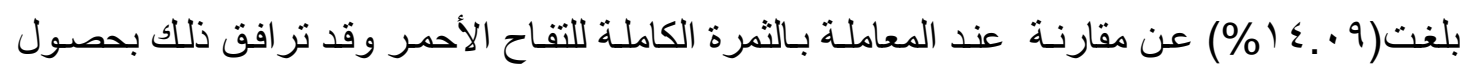

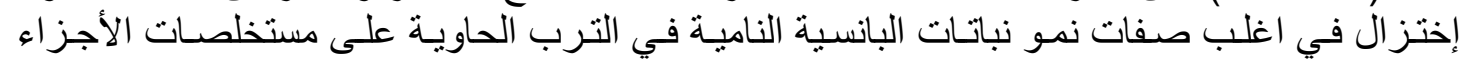

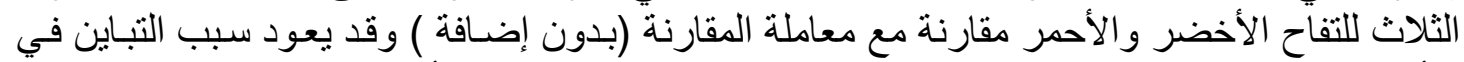

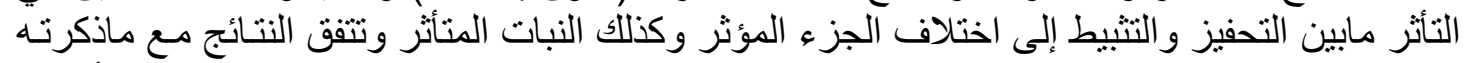

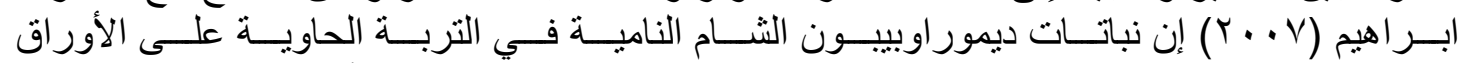

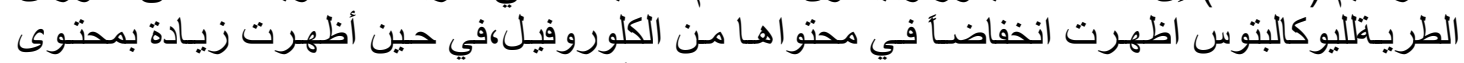

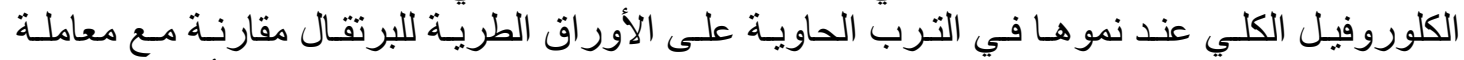

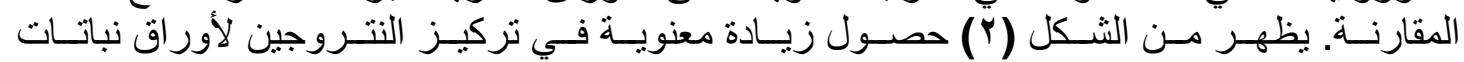

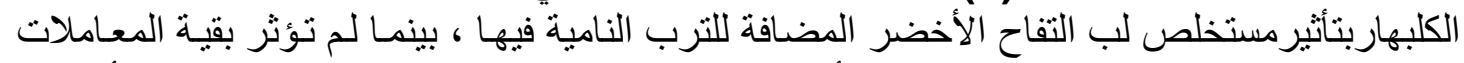

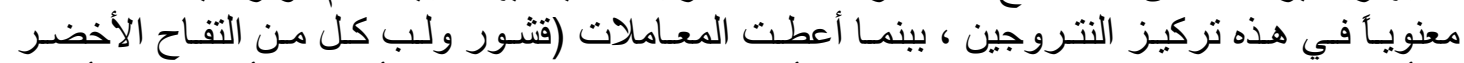

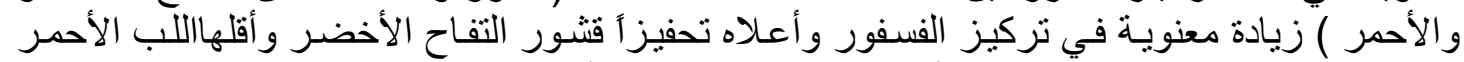

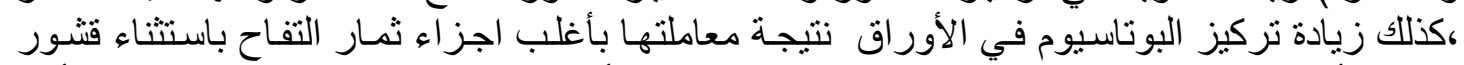

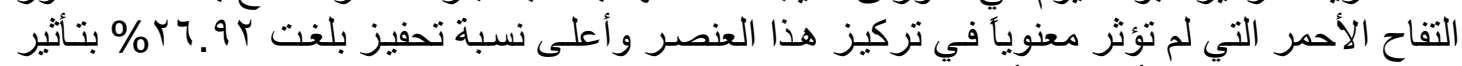

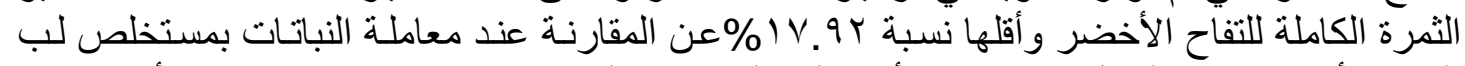

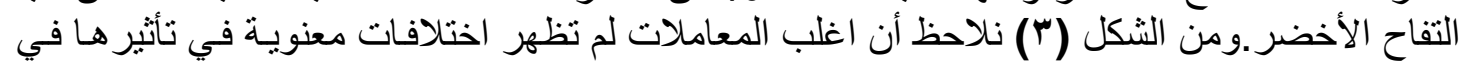




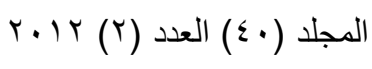

تركيز العناصر لأوراق نباتات البانسية ،حيث لم تثؤثر جميع اجزاء التفاح المضـافة للتربـة في تركيز

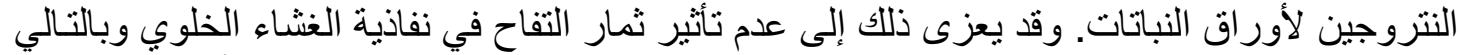

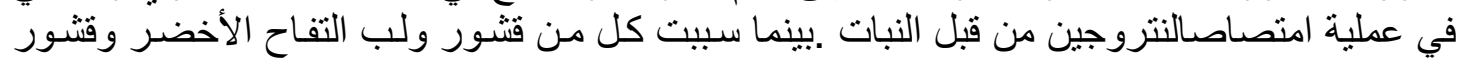

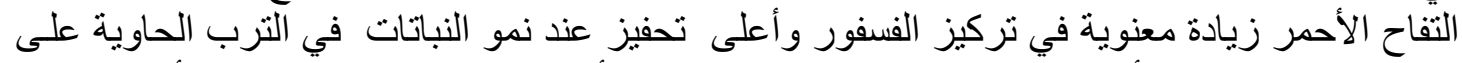

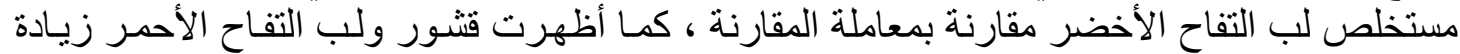

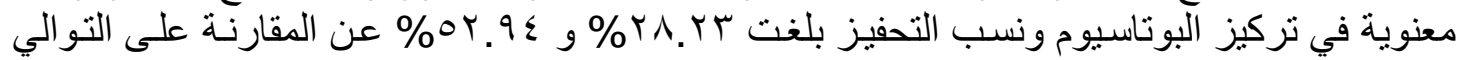

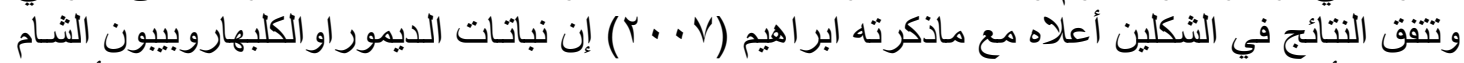

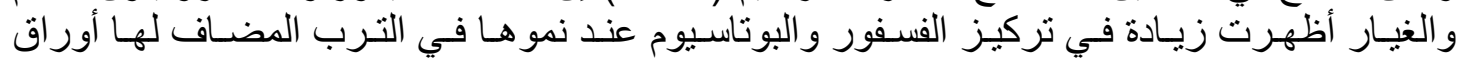

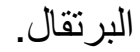

\section{نبات الثبو}

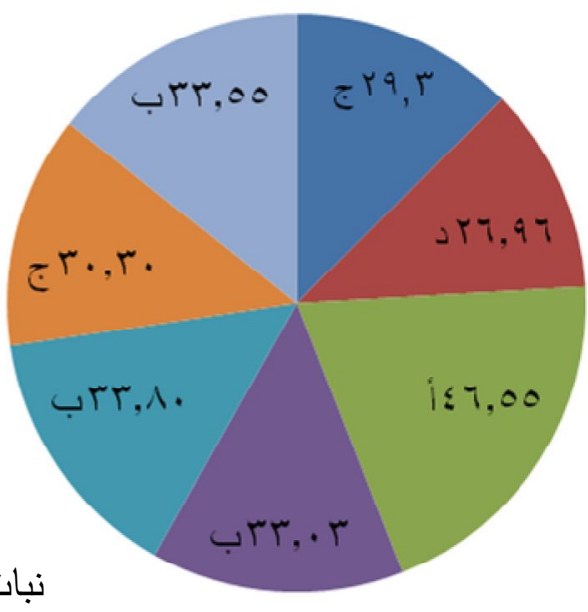

$$
\begin{aligned}
& \text { مقارنة }
\end{aligned}
$$

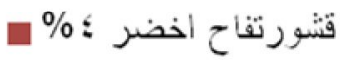

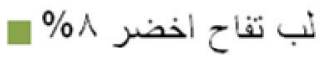

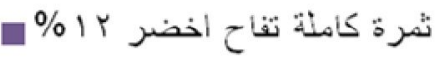

$$
\begin{aligned}
& \text { قتنور تفاح احمر ؛ }
\end{aligned}
$$

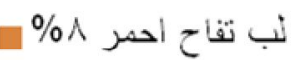

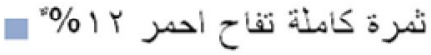

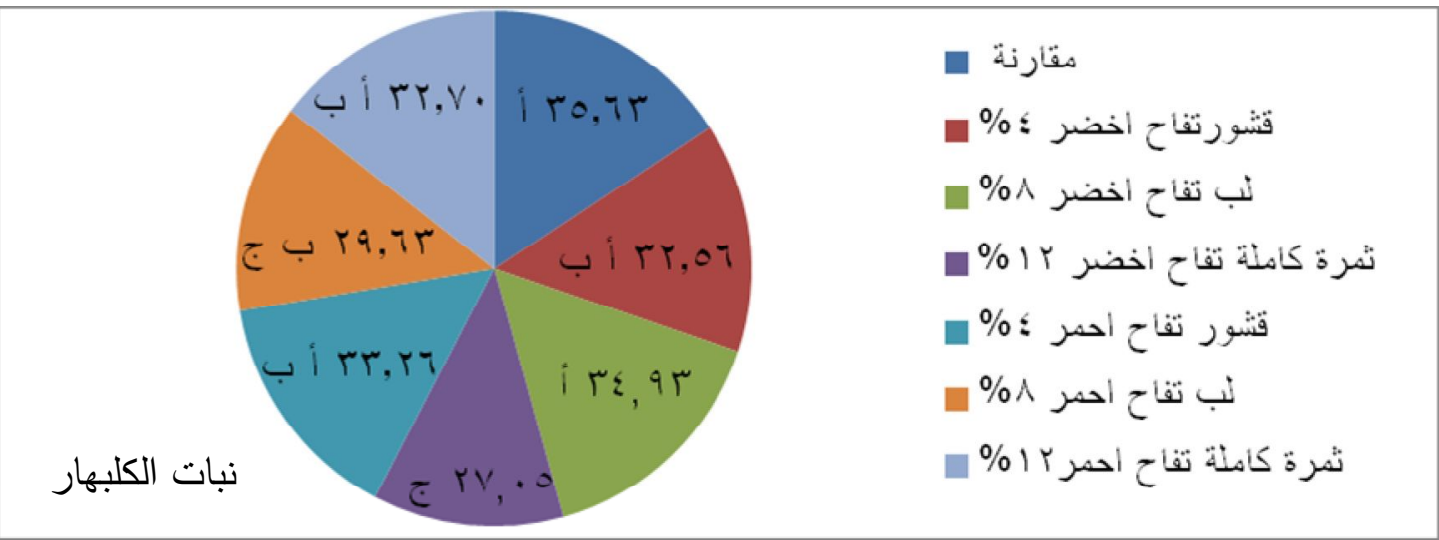

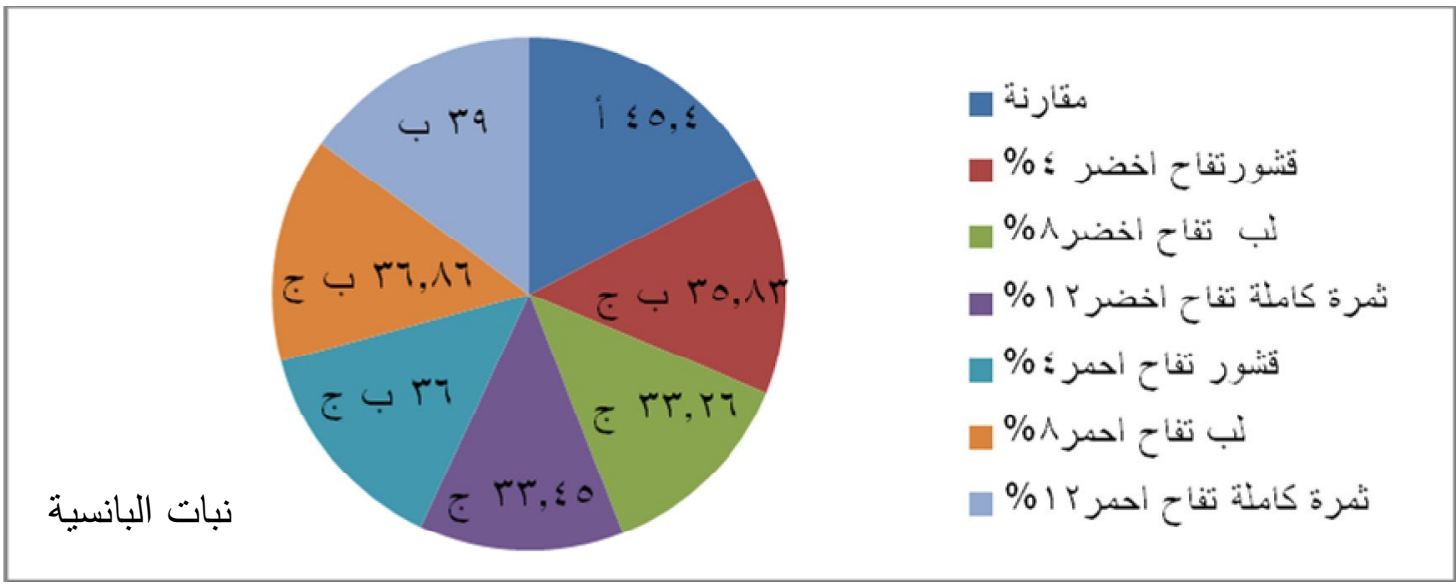



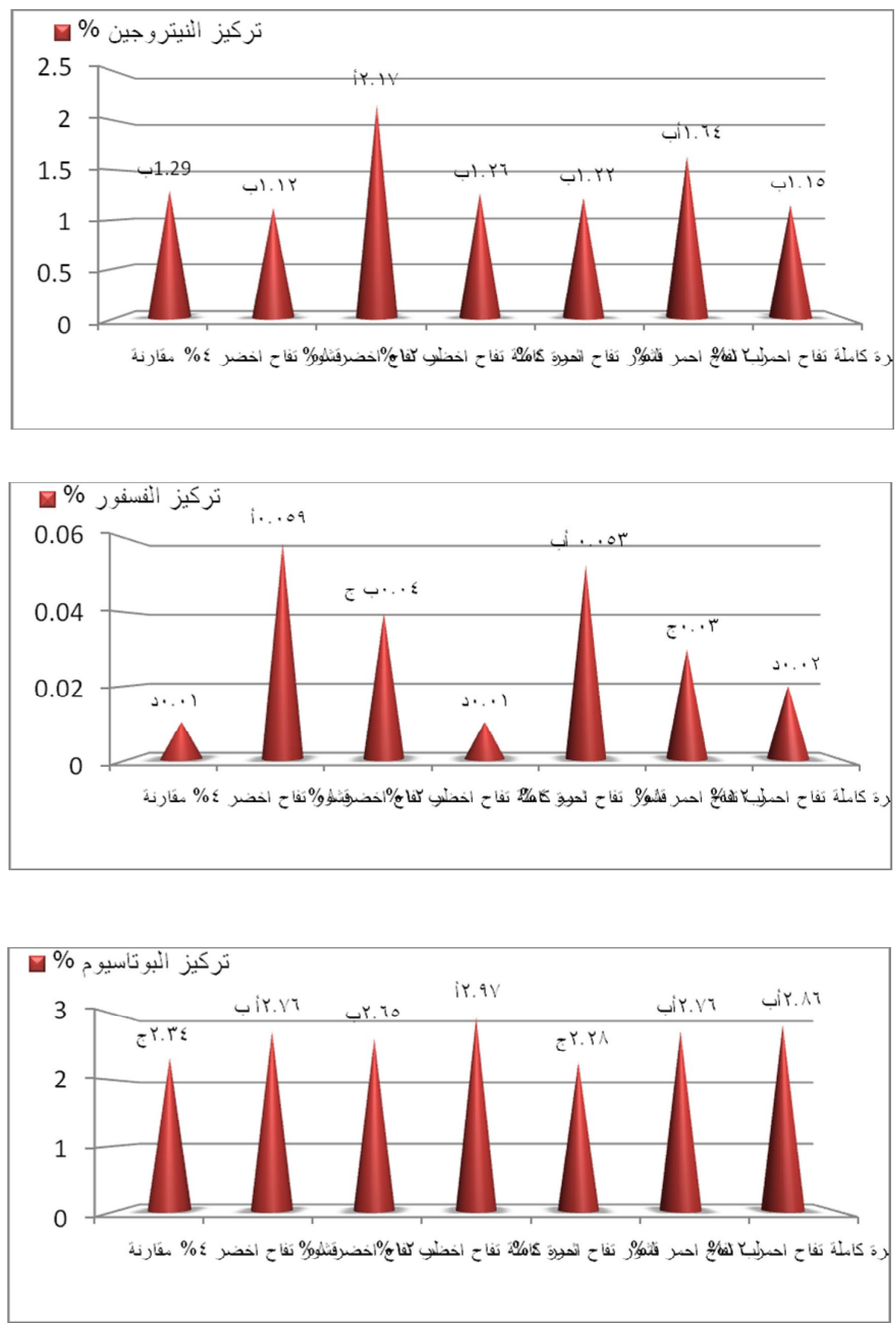

الثكل (Y): يوضح تأثثير التداخل بين اصناف التفاح واجزاء اثماره في تركيز بعض العناصر الغذائية لاوراق نباتات الكلبهار 


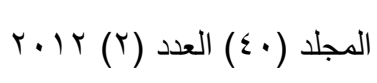
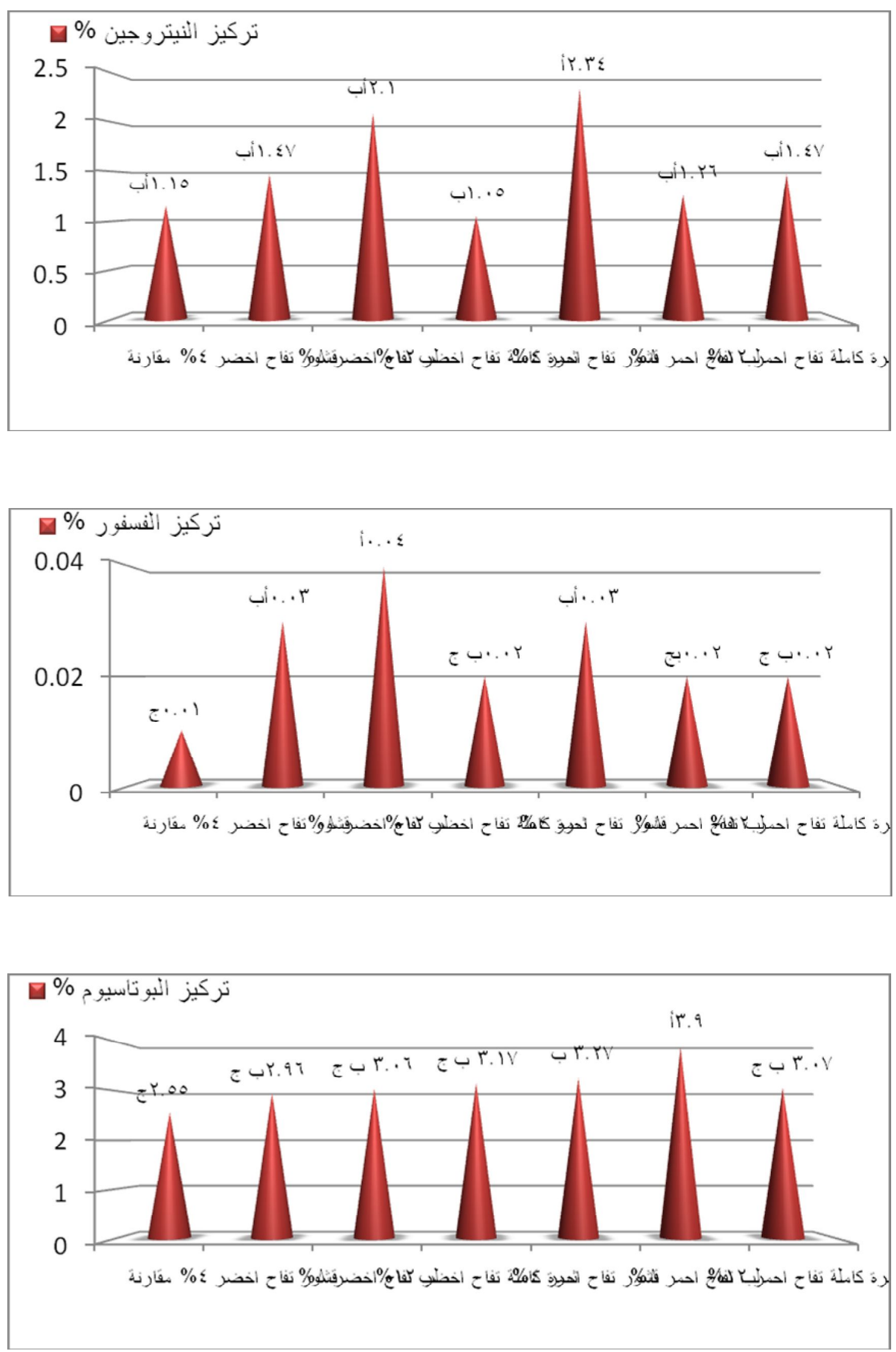

الثكل (ب): يوضح تأثير التداخل بين اصناف التفاح واجزاء اثماره في تركيز بعض العناصر الغذائية لاوراق نباتات البانسيه 


\title{
ALLELOPATHICPOTENTIAL OF WATEREXTRACTOF PARTS FOR TWO APPLE FRUIT VARIETIESONGERMINATIONAND GROWTH SOME ORNAMENTAL PLANTS
}

Salah M. Saied

Abdullah M. Salem

Halla M. Yaqub

Biology/College of Sci. Hort. and Landscape Design/Agric. Biology /Ccollege of Sci.

Mosul University

University

\author{
Mosul University Mosul
}

\begin{abstract}
This research was conducted in green house of Department of Biology/ College of Science/ Mosul University to study the effect of water extracts for green and red apples for their three parts (peal 4\%. pith 8\% and fruit 12\%) to soil in germination and some growth characteristics for the three kinds of ornamental plants which grow in this soil.The results showed that there is a decrease in most of the characteristics of Viola wittrockiana andCalendula officinalis plants except the concentration of the elements potassium and phosphorous where they led to an increase in most of the elements concentration in their leaves. Otherwise. we noticed that there is a differencebetween inhibition and stimulation in some growth characteristics for Mathiolaincana with other plants and control treatment. While concerning the effect of the kinds.the red apple was more inhibitive than green apple. In respect of the other parts. the pith was much effective in most characteristics and the least effect was in the fruit. It was shown also thatViola wittrockiana and Calendula officinalis plants were more sensitive when treating with extracts. while Mathiolaincana gave better growth.

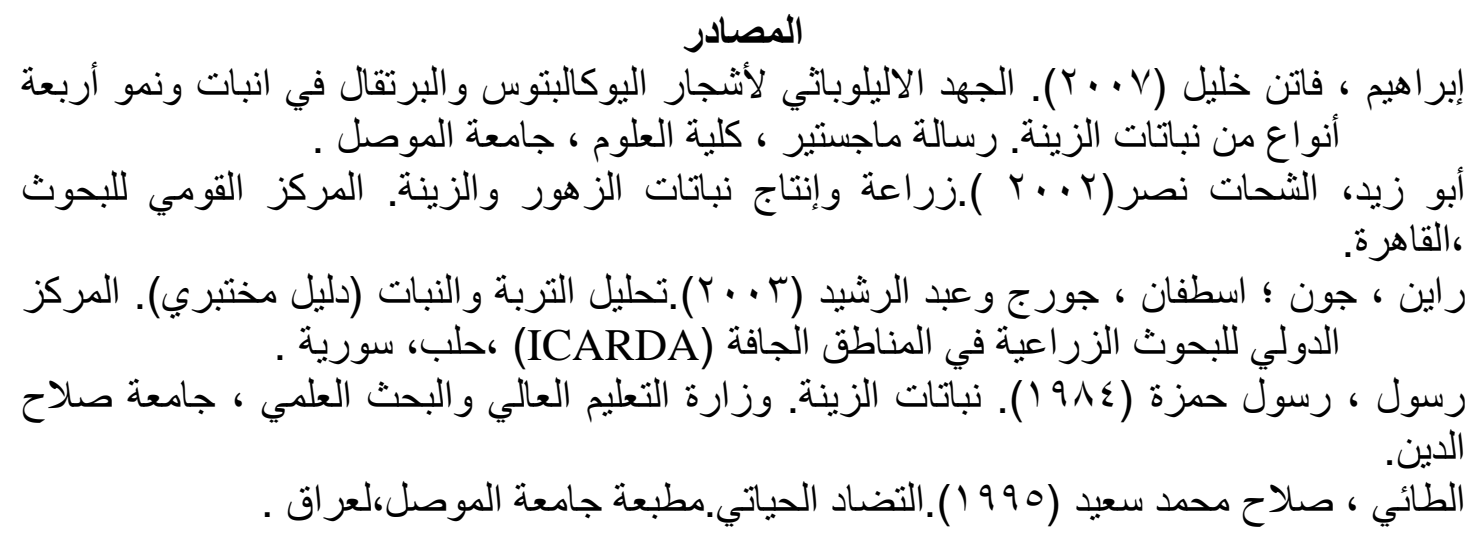

AL-Saadawai. I.S.(2006). Soil sickness in Iraq: possible role of soil fungi and allelopathy . J.Allelopathy..18:47-56.

Anonymous . Institute . (1996) . SAS User's Guide : Statistics . Vertion7Ed . SAS Institute Inc .. Cary . NC. USA.

Black. C.A. (1965). Diognosis and Improvement Of Saline and Alkali U.S.D.A. Handbook. No. 60.Soil.

Chung. I.M.; J.K.Ahn; S.J .Yun(2001).Assessment of allelopathicpotential of costal bermudagrass .Agron . J.80:557-560. 


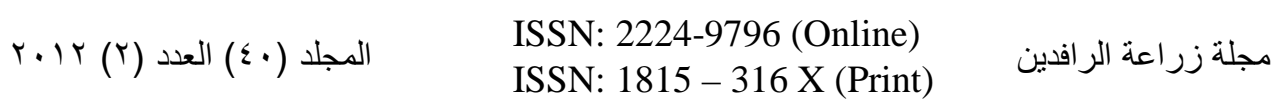

Djurdjevic.L.; M.Mitrovic; A. Dinic; P.Prlovic; S.Bojovic;G.Gajic; O. Kostic(2006). Allelopathic investigation of QuercusconfertaL. And Quercuscerris L.domination in oak forest at Avala Mt.(Serbia) $.13^{\text {th }}$ Australian Agronomy Conference .

Fisher. R.F.; R.A.Woods.; M.R. Glavici( 1978). Allelopathic effects of goldenrod and aster on young sugar maple. Can. J. For. Res.. 8:1-9.

Horsley. S.B.( 1977). Allelopathic inhibition of black cherry by fern. grass. goldenrod. and aster. Can. J. For. Res.. 7:205-216.

Anonymous (1976). International rules for seed testing .Seed Sci. and Tech..34. J. For. Res. 7:205-216.

James. J.F.and R.Bala (2003). Allelopathy ; How Plants Suppress Other Plants. Institute of Food and Agricultural Sci.University of Florida.

Politycka.B. and D.Admaska(2002).Release of phenolic compounds from Apple residues decomposing in soil and the influence of temperature on their degradation.J.Envir..12:95-98.

Rice. E.L. (1984). Allelopathy.2nd Ed.. Academic Press. NewYork. USA.

Steel. R.G.D. ; and J.H.Torrie (1980). Principles and Procedures of Statistics. 2nd Ed.. McGraw - Hill Company. Inc 